\title{
CHINESE ACUPUNCTURE
}

\section{Gordon M. Wyant and Monique Camerlain}

IN RECENT YEARS acupuncture has captured the imagination of both the medical profession and the lay-public, largely due to the efforts of the Government of the People's Republic of China to popularize this method of treatment. Numerous delegations have been invited to witness acupuncture in action and even lay groups touring the country have been treated to the spectacle of operations being carried out under acupuncture anaesthesia. This in turn has raised expectations and a considerable demand on the part of the public for this kind of treatment, while medical delegations on the whole, of course, have been a good deal more skeptical. Nevertheless, their relatively short exposure in China has made it difficult for them to evaluate in depth the validity of what they were shown and since these delegations have as a rule travelled from one city to another, physicians have been unable to follow up the cases they had observed.

This report is based on a three and a half months' experience with acupuncture in the People's Republic of China, three months of which were spent at the Kiangsu College of New Medicine in Nanking on a formal course of "Acupuncture and Moxibustion" with both theoretical and practical instruction. It is based on data obtained from our Chinese colleagues and on personal practical experiences with some 1,000 acupuncture treatments to over 200 out-patients for 52 different diseases.

To understand fully the role which acupuncture plays in the practice of medicine in China and the reasons underlying the upsurge in its popularity in recent years, it is necessary to view Chinese acupuncture in its native environment and from a Chinese perspective. Only when this is fully understood is it possible to attempt extrapolation of the potential uses of this treatment to our own society and patients and to submit it to intelligent and impartial scrutiny. Consequently, some relevant aspects of the present system of health care delivery in China will be described as background information.

\section{Health Care Delivery in the People's Republic of China}

Until the "Great Proletarian Cultural Revolution" which started in 1966 medical education was little changed from what had existed before "Liberation", the term used in China to describe the coming to power of the present regime. This system of medical education was similar to that with which we are familiar and consisted of five to six years of training in medical college followed by an internship. While the quality of physicians produced by this system was high, it was numerically quite inadequate. As a result, while good medical facilities were available in the cities, medical care in the countryside was very sparce where it was available at all

From the Departments of Anaesthesia, University of Saskatchewan and Rheumatology, Université de Sherbrooke.

Canad. Anaesth. Soc. J., vol. 24, no. 1, January 1977 
and, consequently, the majority of the Chinese people, 80 per cent of whom live in the countryside, were for all intents and purposes without medical support. Where medical services did exist the poverty of the average peasant prevented him from availing himself of such facilities.

With the coming of the Cultural Revolution all universities were closed and remained so for a varying length of time, some for as long as seven years. It is not known whether all have been reopened yet. When proper medical training resumed the entire system had been radically revised. In the medical colleges the training of students had been reduced to three years of 11 months each. While this is a substantial but, on the surface, not necessarily fatal reduction of the curriculum, allowance must be made for the fact that a considerable proportion of this time is taken up by political study and manual labour. Students are admitted after they have been recommended by their fellow workers or peasants and when this recommendation has been approved by the local party organization. Preference is given to students who have had either several years of manual labour, have been working as barefoot doctors, or have served in the People's Liberation Army. While they have completed middle school (the equivalent of our grade 12) no cognizance whatsoever is taken of scholastic record, this being replaced by the "political consciousness" of the candidate. All basic sciences are completed in the first year, applied sciences are taught in the first half of the second year; whereupon for the next year and a half the student is given practical tuition, much of which is taken in county and commune hospitals and in factory clinics. Great stress is laid on the fact that the student and, later on, the doctor, does retain his original roots in the country or the factory whence he came. Once admitted to medical college all is clear sailing. Examinations are by "open book"; failures and drop-outs are unknown.

A second category of physicians is produced in medical schools as opposed to medical colleges. These institutions provide a two-year course after which the graduate also is referred to as "doctor."

The third category of "doctors" are the barefoot and the worker doctors. These are produced originally in a three- to six-month course in which they are said to learn the elements of medicine, the recognition of the common diseases in their community and their treatment with both traditional and Western medicines, the recognition of medicinal herbs, and the provision of preventive medical services. Refresher courses, usually of one month duration, are provided every year in the appropriate county hospital; some may be chosen to take longer instruction which may enable them to carry out surgical operations. Alternatively, some may gain admission to a medical school or medical college.

The fourth category of physicians is of course provided by those who qualified under the old system before 1966. They enjoy no particular privileges or prestige

\footnotetext{
"The term "barefoot doctor" is reserved for those who, irrespective of length of training, have come into medicine from the countryside and must return there to practice. There they continue to work in the fields and traditionally the Chinese peasant does not wear shoes when at work.

Communes are subdivided into a number of "production brigades" and these in turn are made up of "production teams." Barefoot doctors and worker doctors sponsored by their respective production brigade or factory are obligated after training of whatever length to return to their place of origin. Barefoot and worker doctors as opposed to "medical workers" in the cities are not specifically paid for their medical services but earn their work points like all other members of the commune, or production brigade, or factory.
} 
vis-a-vis all other "doctors." Indeed it is entirely impossible to distinguish one from the other. It is evident from the foregoing that in a commune hospital or indeed even in the medical facility at production brigade level, there may be the odd three-year physician, but most will have any amount of training down to the minimum of three to six months. With 1,500 barefoot doctors, the countryside is now very well provided with medical services of one kind or another.

One word about hospitals: these are quite poorly maintained and rather scantily equipped by our standards. Most of the equipment used in the average city hospital is antiquated; even the major teaching hospitals' auxiliary services, such as laboratory facilities are primitive by comparison. In keeping with the policy statement by Chairman Mao: "In medical and health work put the stress on the rural areas" we have found some county hospitals relatively better equipped than some large city hospitals. Very modem equipment of all sorts is being produced in China, but apparently in limited quantities. In some hospitals it is kept in reserve for special indications only.

All city hospitals are required to send mobile teams to flesh out the services at county hospitals and usually one third of the medical staff are absent on these duties at any given time. The average time of service in a mobile team is six months. During this time physicians in county and commune hospitals are being up-graded and refresher courses are being provided. Thus a network of medical services has been created which encompasses the whole of China and provides a quantitative service to the vast majority if not to all Chinese citizens.

Unfortunately what must be seen as a crash program to fill a vacuum and provide at least some services to all parts of China has now become an end in itself, and an attempt is made to convince the world that this is a desirable permanent solution to all manpower problems in medicine. The internal political struggle between the incumbent administration and more moderate "revisionists" had amongst many other matters also concerned itself with precisely this subject. The now disgraced Teng Hsiao-Ping" put it that it was his aim in the long run "to put shoes onto the barefoot doctors," in other words to upgrade the training so that in another generation medical services would be adequate both quantitatively and qualitatively. Since this particular segment of political opinion did not carry the day, there is now no prospect of this being done in the foreseeable future. One is therefore left to wonder whence will come the teachers to instruct the next generation once the pre-1966 physicians are no longer.

\section{Acupuncture Analgesia}

While acupuncture was in eclipse during the last Imperial Dynasty and under the Kuomintang regime, the communists during their struggle for political supremacy which largely took place in remote parts of China, found acupuncture an easily available mode of treatment which was economic of scarce manpower, equipment and supplies. With the establishment of the People's Republic this mode of treatment was much encouraged and the practitioners of traditional medicine were brought out of obscurity and enjoyed a hitherto unknown degree of recognition

'Recent political events in China may call for re-evaluation of some of these statements. 
and relative prosperity, in conformity with one of the most frequently quoted policy statements by Chairman Mao: "Chinese medicine and pharmacology are a great treasurehouse and efforts should be made to explore them and raise them to a higher level."

This trend was much accelerated by the Cultural Revolution and when medical colleges finally reopened they all included in their curriculum the teaching of Traditional Chinese Medicine, including acupuncture and herbal medicine. Those institutions whose primary emphasis still is on westem medicine now also teach a course of Traditional Chinese Medicine, while the traditional colleges emphasize their particular mode of medicine and put less stress on westem concepts. In this way an attempt is made to blend Traditional Chinese Medicine with Western Medicine with the emphasis and encouragement definitely being given to the traditional methods of treatment.

Acupuncture is an ancient art of healing going back to the "Canon of Medicine (Nei Jing)," a work written some 2,500 years ago. While in the course of the intervening centuries some additions and refinements have been made, yet all acupuncture therapy is still based ultimately on the theories and concepts of treatment enunciated in that work. This is not the place to discuss in detail the basis of Traditional Chinese Medicine. Suffice it to say that its concepts of physiology and pathogenesis are totally alien to us. Hence a complete reorientation in thinking is needed before one can even begin to understand the rationale of treatment. While no physician trained in Western medicine can intellectually accept some of the basic concepts, nevertheless one must comprehend them since upon this foundation has been erected, in an entirely logical fashion, the edifice of Traditional Chinese Medicine and in particular the practice of acupuncture and moxibustion. Some examples may be helpful to illustrate the dilemma in which a Western-trained physician finds himself when coping with an understanding of Chinese Traditional Medicine. In the Chinese concept, which has not changed since the days of the "Canon of Medicine," there are six solid or zang organs paired with six hollow ones $(f u)$. While the pairing off of the kidney with the urinary bladder and of the liver with the gallbladder can be easily understood, the combinations of lung with large intestine, heart with small intestine, and spleen with stomach are somewhat more difficult to comprehend, unless one remembers, for instance, that the spleen is considered to govern digestion, absorption and transportation of food. No such relatively logical explanation exists for the combination of the others. The sixth zang organ is the pericardium, again a difficult concept to assimilate. Furthermore, each solid organ is said to relate to one of the sense organs: for instance the kidney is related to the ear, the liver to the eye, and so on. Each of the regular channels (more commonly called meridians in the West) is related to one of the zang or $f u$ organs and thus it follows that apart from the kidney channel, the urinary bladder channel also can be used for the treatment of diseases of the kidney, and either or both for diseases of the ear. Of course, the whole system is much more complicated and this example is only given to emphasize again the difficulties faced by the Western-trained physician when confronted with traditional Chinese thinking. In the clinical application of acupuncture one of the most vexing problems is the relation of most syndromes to the six exogenous 
pathogenic factors of heat, cold, damp, wind, dry and fire. Again an entire edifice of pathology and consequent treatment is erected on that basis. If one adds to all this the concepts of Yang and Yin, of Xue (blood) and Qi (vital energy), as well as eight extraordinary channels, extra points not related to channels, and points with special significance, one can get some idea of the myriad of possible therapeutic combinations which present themselves in each case. It is almost possible to justify any acupuncture point or combination of points by the judicious application of these intricate relationships. The cynic might conclude that it is entirely immaterial what points are selected in any particular case. There is, of course, some evidence in the Western literature that indeed there may be no specificity to the selection of points, although this would be hotly disputed by knowledgeable Chinese practitioners of Traditional Medicine.

While good results can be achieved with acupuncture in the treatment of pain, this is more dramatically evident in acute than in chronic pain. Acute painful conditions can often be treated by one or two acupuncture sessions while for chronic pain many sessions or even courses of treatment may be required until complete or partial relief has been attained. It is important to emphasize at this point that since acupuncture will only relieve the symptom of pain, the underlying condition must be diagnosed and treated by conventional methods. In this regard the use of acupuncture must be different in Western countries from the practice in China since there acupuncture is looked upon as a finite therapeutic entity, largely because the Chinese tend to concentrate on treating symptoms rather than the causes of disease. On this basis acute appendicitis, tonsillitis, cholecystitis and mastitis, renal colic, etc., are being treated by acupuncture alone or in combination with herbal medicine. Other diseases, especially those of an infectious nature, including, for instance, acute bacillary dysentery and malaria, are said to be amenable to acupuncture. On the other hand no Chinese would advocate acupuncture as a treatment of obesity, to stop smoking, for mammoplasty, face-lifts and such like, as is being done now in some countries.

Another difficulty in the evaluation of acupuncture is the almost total absence of comparative studies. We have seen patients treated with acupuncture for the sequelae of apoplexy who indeed may have shown partial return of function in a paralyzed limb or limbs. However, no comparative series are available for patients treated by conventional methods and without acupuncture. Nor is the role of concomitant therapy clear in all cases. Other diseases for which cures by acupuncture are being claimed are of a self-limiting nature and again no comparative studies are available to determine the advantages, if any, of acupuncture.

We have seen no conclusive evidence that acupuncture can cure any disease. One must therefore come to the conclusion that while Chinese acupuncture may well have a place in the management of pain, its true place in western medical practice remains to be identified.

No report on acupuncture would be complete without mention being made of moxibustion and cupping, both of which are extensively practiced in conjunction with acupuncture. Moxibustion refers to a technique of producing local warmth through the burning of moxa, a slow-burning preparation of the dried leaves of "artemesia vulgaris." This may be applied either by holding a stick of compressed 


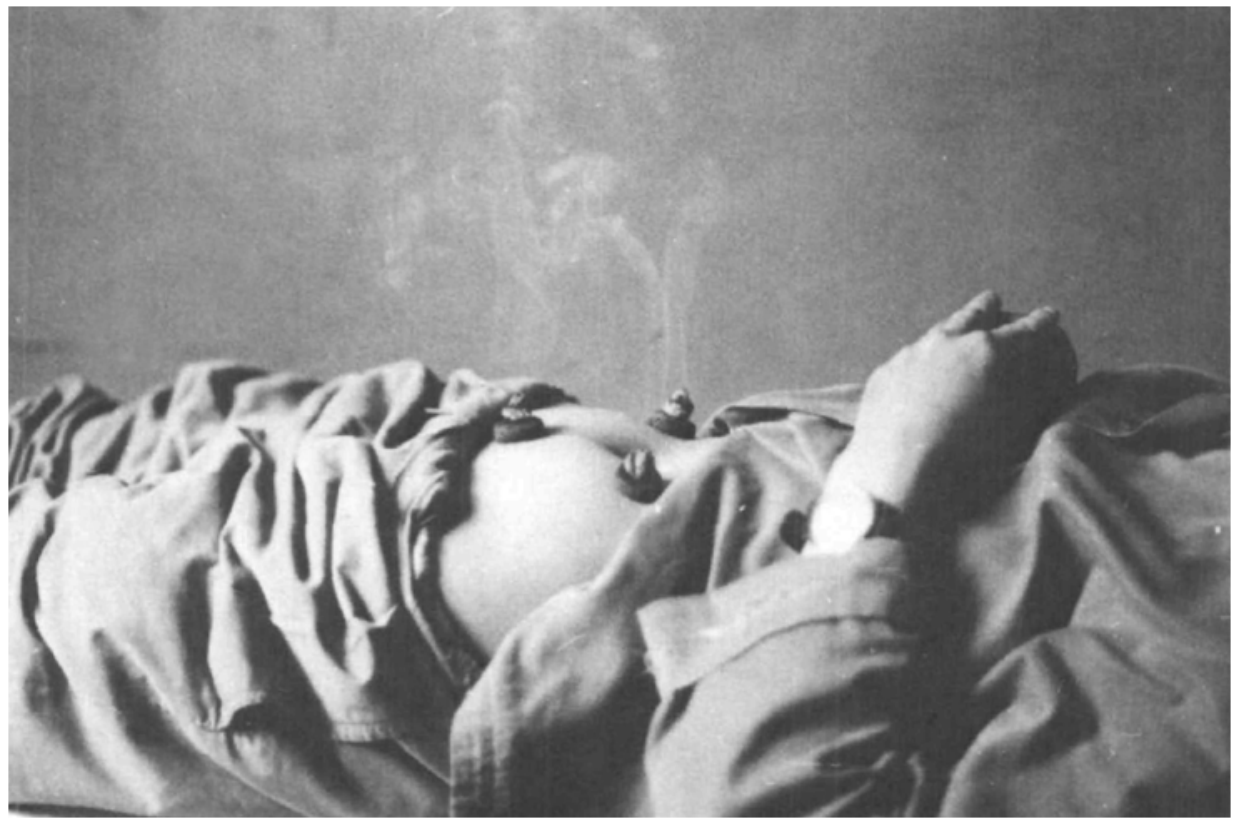

Ficure 1. Moxibustion with interposed slice of aromatic substance. The moxa cone has been set on top of the acupuncture needle (note smoke rising from the slow-burning moxa). In keeping with the Chinese practice of not undressing patients for examination or treatment, only a minimum of skin is exposed.

moxa over the area to be heated or by applying it by means of a cone fashioned from loose moxa wool and applied direct or on top of the acupuncture needle. A modification of this technique is the interposition between the patient's skin and the moxa of salt, a slice of ginger or garlic (Figure 1). Cupping refers to the production of local hyperaemia through the application of a cup or cups made of bamboo or glass from which the air has been evacuated. This also is frequently practiced in conjunction with or following acupuncture, a somewhat extreme example of which is shown in Figure 2. This is an ancient form of treatment which once upon a time was practiced extensively also in western countries.

\section{ACUPUNCTURE ANAESTHESIA}

That the analgesic properties of acupuncture should be utilized for the provision of surgical anaesthesia was a logical next step in its development. The first attempts at inducing acupuncture anaesthesia were undertaken at Shanghai in 1958 and were then developed in a number of centres to the point where acupuncture anaesthesia now occupies a major role in the operating rooms of all hospitals throughout China. While body needling remains the most popular mode of providing acupuncture anaesthesia for surgical operations, some hospitals in Nanking have pioneered the use of ear acupuncture for that purpose and have found it equally useful and a good deal simpler because of the concentration of needles in one place and usually well within the field of observation of the anaesthetist. The simplicity 


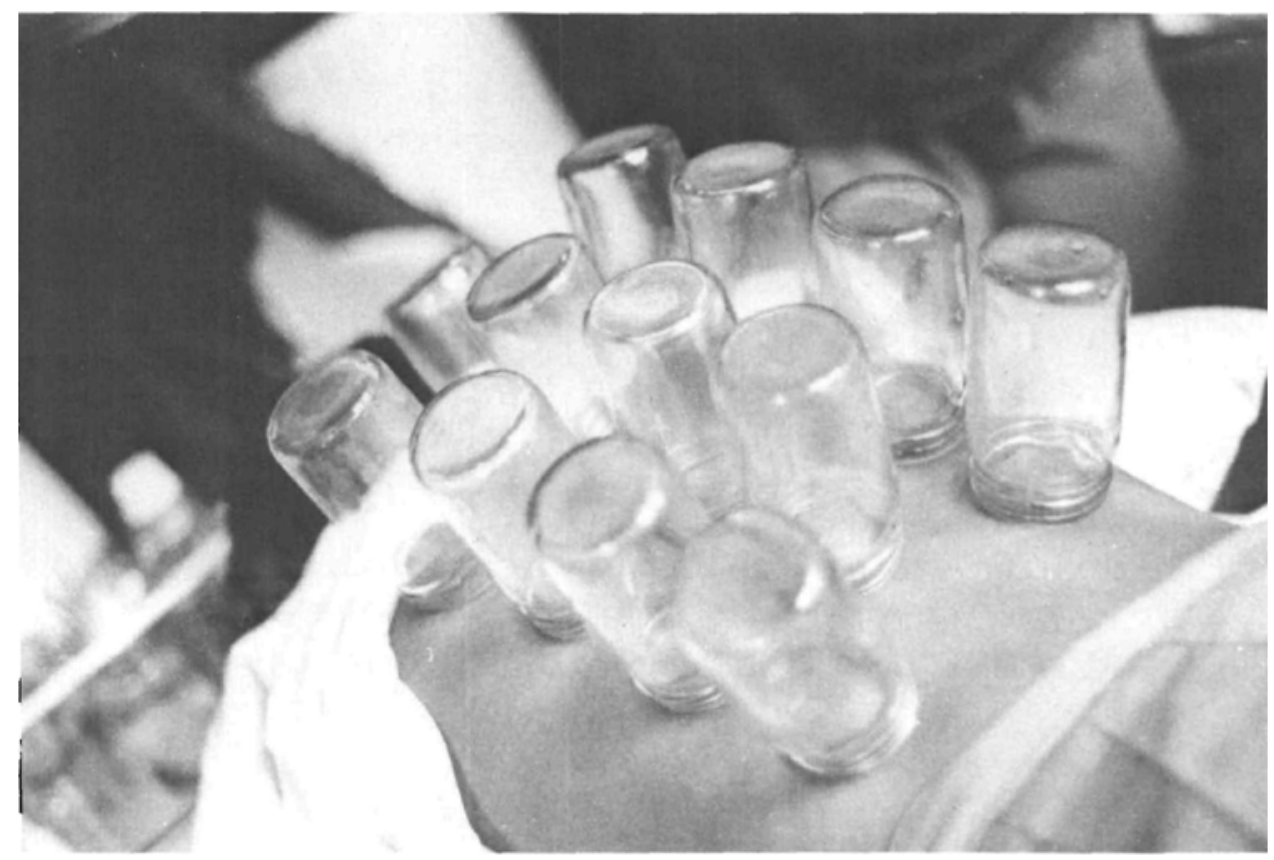

Figune 2. "Cluster" cupping.

of acupuncture anaesthesia has made it particularly suitable for use by partially trained "doctors" nurses, and technicians. While acupuncture anaesthesia is more successful in some kinds of operations than in others, with procedures on the neck being attended by the best results, it has been used in all surgical specialties, including cardio-pulmonary bypass operations (Tables I and II). As time progressed the number of needles for each operation has been reduced; for instance from 56 points originally for pneumonectomy to one to four needles presently. Electrical stimulation has largely superseded manipulation of acupuncture needles by hand during surgical operations. The technique has been extended also now into Veterinary operations on cattle, pigs, horses and donkeys for such procedures as Caesarean section and entero-anastomosis, while cats and rabbits have largely been used for experimental purposes.

\section{Effectiveness and Properties of Acupuncture Anaesthesia}

To assess the effectivenes of acupuncture anaesthesia, results are assigned one of four grades. Grade I is defined as essentially no pain throughout the procedure or at most slight discomfort at some stages of the operation. The patient remains calm and there are only slight changes in blood pressure, pulse and respiration. Supplementation of analgesia by meperidine 1 to $1.5 \mathrm{mg} / \mathrm{kg}$ is permitted within a two-hour surgical period. No local anaesthetic supplement is being used. Grade II denotes analgesia characterized by more marked pain at certain stages of the procedure but the operation can still be accomplished without difficulty. There may be occasional gentle moaning on the part of the patient with slight changes in blood pressure, pulse and respiration. Supplementary doses of meperidine are allowed 
TABLE I

Effectiveness of Acupuncture Anaesthesia. I (Unidentified Shanghai Hospital; up to May, 1973)

\begin{tabular}{|c|c|c|c|c|}
\hline Type of operation & $\begin{array}{l}\text { No. of } \\
\text { cases }\end{array}$ & $\underset{\text { I }}{\text { Grade }}$ & $\begin{array}{l}\text { Grades } \\
\text { I and II }\end{array}$ & $\begin{array}{l}\text { Effective rate } \\
\text { (I, II and III) }\end{array}$ \\
\hline $\begin{array}{l}\text { Craniotomy } \\
\text { Operation for } \\
\text { detachment of retina }\end{array}$ & $\begin{array}{l}606 \\
374\end{array}$ & $\begin{array}{l}\% \\
34.65 \\
32.2\end{array}$ & $\begin{array}{c}\% \\
70.3 \\
73.6\end{array}$ & $\begin{array}{c}\% \\
96.2 \\
80.7\end{array}$ \\
\hline $\begin{array}{l}\text { Operation on thyroid } \\
\text { Total laryngectomy } \\
\text { Pulmonary resection } \\
\text { Mitral commissurotomy } \\
\text { Open-heart operation } \\
\text { under extra-corporeal } \\
\text { cardio-pulmonary } \\
\text { circulation }\end{array}$ & $\begin{array}{r}670 \\
121 \\
656 \\
106 \\
72\end{array}$ & $\begin{array}{l}54.5 \\
53.7 \\
17.7 \\
33 \\
12.5\end{array}$ & $\begin{array}{l}85.7 \\
83.5 \\
43.7 \\
74 \\
77.8\end{array}$ & $\begin{array}{l}95.4 \\
92.6 \\
96.5 \\
95 \\
87.5\end{array}$ \\
\hline $\begin{array}{l}\text { Subtotal gastrectomy } \\
\text { Abdominal hysterectomy } \\
\text { Internal fixation of } \\
\text { fractured neck of } \\
\text { femur with three-flanged } \\
\text { nail }\end{array}$ & $\begin{array}{l}763 \\
590 \\
462\end{array}$ & $\begin{array}{l}16.9 \\
34.4 \\
51.9\end{array}$ & $\begin{array}{l}61.9 \\
79.9 \\
90.5\end{array}$ & $\begin{array}{l}96.1 \\
87.4 \\
96.5\end{array}$ \\
\hline
\end{tabular}

TABLE II

Effectiveness of Acupuncture Anaesthesia. II

(No. 2 Teaching Hospital, Nanking; up to 1974)

\begin{tabular}{lccccc}
\hline \hline \multicolumn{1}{c}{ Type of operation } & $\begin{array}{c}\text { No. of } \\
\text { cases }\end{array}$ & $\begin{array}{c}\text { Varieties of } \\
\text { operations }\end{array}$ & $\begin{array}{c}\text { Grade } \\
\text { I }\end{array}$ & $\begin{array}{c}\text { Grades } \\
\text { I and I }\end{array}$ & $\begin{array}{c}\text { Effective rate } \\
\text { (I, II and III) }\end{array}$ \\
Neurosurgical & & & $\%$ & $\%$ & $\%$ \\
Ophthalmology & 171 & 20 & 24.5 & 74.85 & 95.32 \\
ENT & 299 & 20 & 36.1 & 82.61 & 88.96 \\
Thyroid ops. & 185 & 18 & 40 & 78.27 & 90.23 \\
Pulmonary resection & 260 & 4 & 75 & 94.62 & \\
Subtolal gastrectcmy & 850 & & 26.6 & 93.33 & 96.52 \\
Atppendectomy & 306 & & 23 & 74.8 & 94.6 \\
Tubal ligation & 179 & & 12 & 59.8 & 85.29 \\
Orthopaedic ops. & 118 & 17 & 26.2 & 74.3 & 96.8 \\
& 2,575 & & 18.6 & 62.37 & 84.74 \\
& & & & \\
\hline
\end{tabular}

as in Grade I and infiltration with small doses of local anaesthetic may be necessary. In Grade III there is sometimes severe pain superimposed on almost continuous discomfort, but the operation can still be accomplished. There are relatively strong responses on the part of the patient with marked changes in blood pressure, pulse and respiration. In this grade the doses of meperidine amount to 1.5 to $2 \mathrm{mg} / \mathrm{kg}$ over a two-hour period and somewhat larger doses of local anaesthetic need to be administered. Grade IV is characterized by severe pain with very marked changes in blood pressure, pulse and respiration and some other form of anaesthetic is required to permit completion of the operation. In all statistics published, only Grade IV is considered a failure, whereas Grades I, II and III are included in the "effective rate." Tables I and II give percentages for the most common surgical fields in which acupuncture anaesthesia has been employed and for some specific 
TABLE III

Comparison of Acupuncture and Drug Anaesthesia Excision of Acoustic Neuroma

\begin{tabular}{|c|c|c|}
\hline & $\begin{array}{l}\text { Acupuncture } \\
\text { anaesthesia }\end{array}$ & $\begin{array}{c}\text { Drug } \\
\text { anaesthesia* }\end{array}$ \\
\hline Number of cases & 20 & 20 \\
\hline \multicolumn{3}{|l|}{ Blood pressure } \\
\hline fluctuation $\quad 20 \mathrm{~mm} \mathrm{Hg}$ & 13 & 12 \\
\hline $30-50 \mathrm{~mm} \mathrm{Hg}$ & 3 & 5 \\
\hline $50 \mathrm{~mm} \mathrm{Hg}$ & 4 & 3 \\
\hline \multicolumn{3}{|l|}{ Pre-operative changes: } \\
\hline pulse rate up $20 \%$ or more & 2 & 10 \\
\hline respiration rate down $10 / \mathrm{min}$ & 2 & 9 \\
\hline temporary apnoea & - & 2 \\
\hline \multicolumn{3}{|l|}{ Post-operative status: } \\
\hline awake at completion of operation & 20 & - \\
\hline within six hours & & 13 \\
\hline after six hours & & 7 \\
\hline no return of consciousness & & 2 \\
\hline special care required beyond first 24 hours & - & 10 \\
\hline \multicolumn{3}{|l|}{ Complications } \\
\hline Pulmonary infection & - & 2 \\
\hline Damage to brain stem and cranial nerves & - & 2 \\
\hline \multicolumn{3}{|l|}{ Cause of death } \\
\hline Pulmonary infection & - & 1 \\
\hline Displacement and damage of brain stem & - & 2 \\
\hline
\end{tabular}

*Drug anaesthesia was defined as diethyl ether in oxygen.

operations. From the above definitions it will be seen that at best Grade I can be considered acceptable by our standards and even in this category the acceptance of slight discomfort might make the method unsuitable for many patients (and surgeons). The relativity of the grading system may best be appreciated by the statement of one of our lecturers who had an appendectomy performed under acupuncture anaesthesia. He stated that he felt sharp pain during the skin incision but that this really was unimportant because it did not last long, that he felt discomfort when the meso-appendix and appendix were clamped and removed, but that after all this also did not last long and that he felt the skin sutures but that this also was of short duration. He proudly related that his anaesthetic was considered Grade I.

One of the advantages of acupuncture anaesthesia which is continuously being quoted by the Chinese is its great margin of safety. This was illustrated by the exhibition of Table III which at first sight indeed seems to confirm a remarkable safety margin vis-a-vis "drug" anaesthesia. However, the information was eventually elicited that drug anaesthesia is defined as diethyl ether in oxygen, apparently the standard general anaesthetic in China. Indeed, the standard anaesthesia machine found in all hospitals is not equipped for administration of any other gases or anaesthetic agents (Figure 3). Consequently statistics are weighted heavily in favour of acupuncture anaesthesia and ignore the great improvements in modern anaesthetic drugs and techniques in Western countries. Nevertheless, it must be conceded that there might be less physiological disturbances with a quicker postoperative recovery, in view of the fact that no chemicals need be metabolized and excreted. It is quoted that after abdominal operations under acupuncture anaesthesia normal peristalsis returns within 24 hours and no gastric tube is required. 


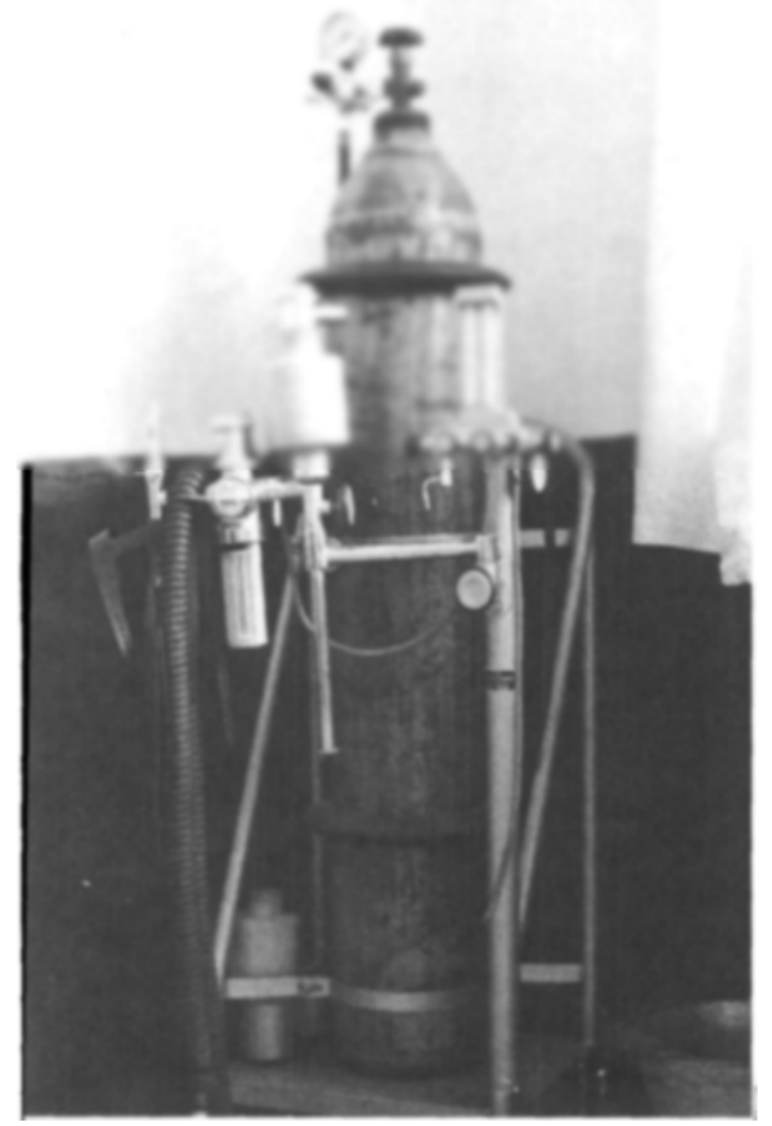

Figure 3. Standard anaesthesia machine found in most Chinese hospitals. The large tank contains oxygen; flowmeters are for fine and coarse flows. The machine has a wick-type vapourizer and a small soda-lime canister.

The low incidence of post-operative retention of urine is also quoted, a 10 per cent figure in this respect being given after haemorrhoidectomy.

Another advantage is the subjective initiative which the patient can bring to bear upon the operation, such as his ability to assist with the identification of muscles during transplantation procedures and the identification of impending damage to the recurrent laryngeal nerve during thyroidectomy. On the other hand such co-operation requires attitudes perhaps more often found in orientals than in occidental cultures. Nevertheless, the fact that acupuncture anaesthesia is simple, economical and practical is a matter of great importance, especially within the Chinese context (Figure 4).

Much speculation has been heard about possible preparation of patients by means of drugs to explain the efficacy of acupuncture anaesthesia. It can be stated quite unequivocally here that drug preparation of patients before acupuncture anaesthesia is not a factor in its success. Either intramuscular sodium phenobarbitone $0.1 \mathrm{gm}$ is given one hour before operation or intravenous meperidine $1 \mathrm{mg} / \mathrm{kg}$ 


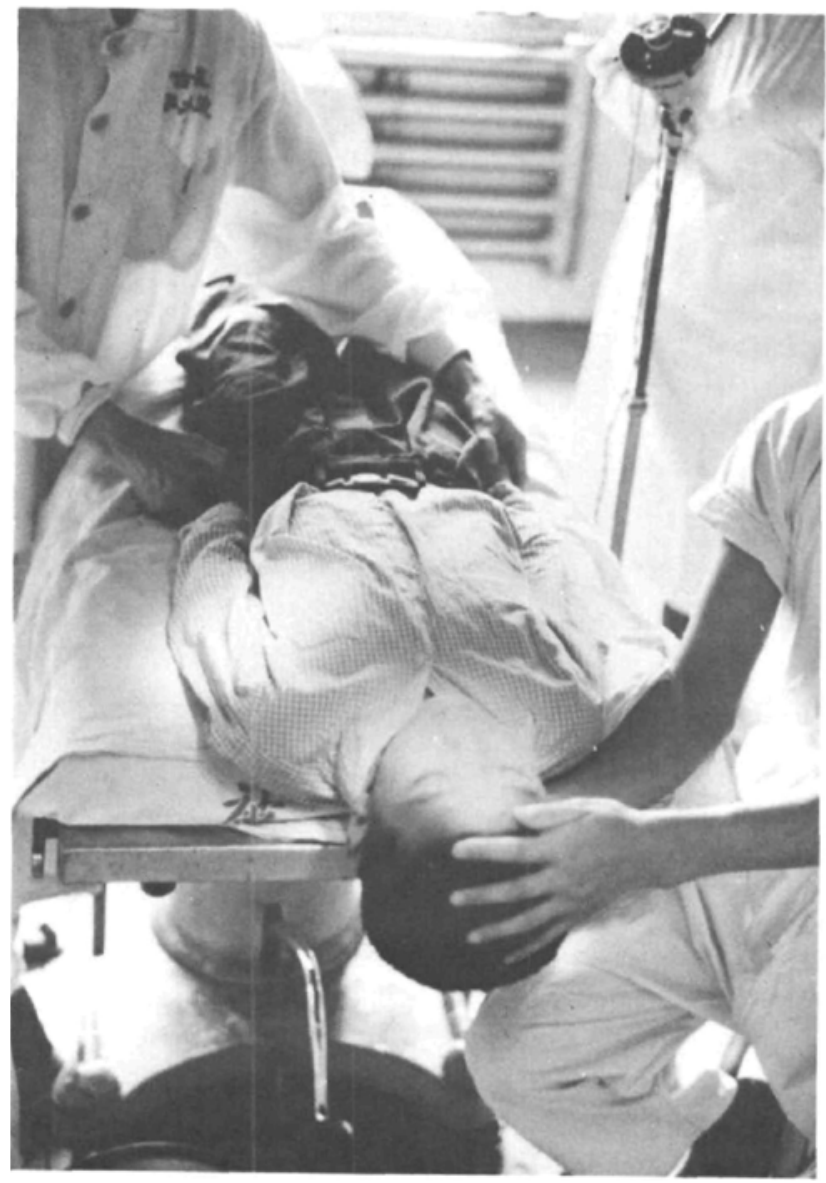

Frgune 4. Preparation for tonsillectomy. Analgesia is produced by massage of point "hegu" on radial side of midshaft of second metacarpal. Note that patient is in his street-clothes, although the operation is being carried out in the operating suite.

10 to 15 minutes before operation. To this atropine $0.5 \mathrm{mg}$, or scopolamine $0.3 \mathrm{mg}$ are added, also one hour before operation. During operation, if required, chlorpromazine, diazepam, meperidine, or fentanyl may be administered in appropriate doses, either intravenously or intramuscularly. Procaine or lidocaine are in some instances used for infiltration or nerve block at the time of the skin incision or closure, or when traction must be exerted upon viscera.

The only other preparation consists of a 'needling test'. This is carried out usually the day before the operation to test the patient's pain tolerance, to relieve anxiety and acquaint him with the needling sensation. Detailed information is also given to the patient to raise confidence and to get his co-operation, two extremely important factors in the success or otherwise of the anaesthetic procedure. The necessity of the operation, its special characteristics, anticipated result and problems are explained in detail. In practical terms then, the percentages of successful procedures must be viewed as applying to an already pre-selected patient population and would presumably be lower if extrapolated to the population as a whole. 


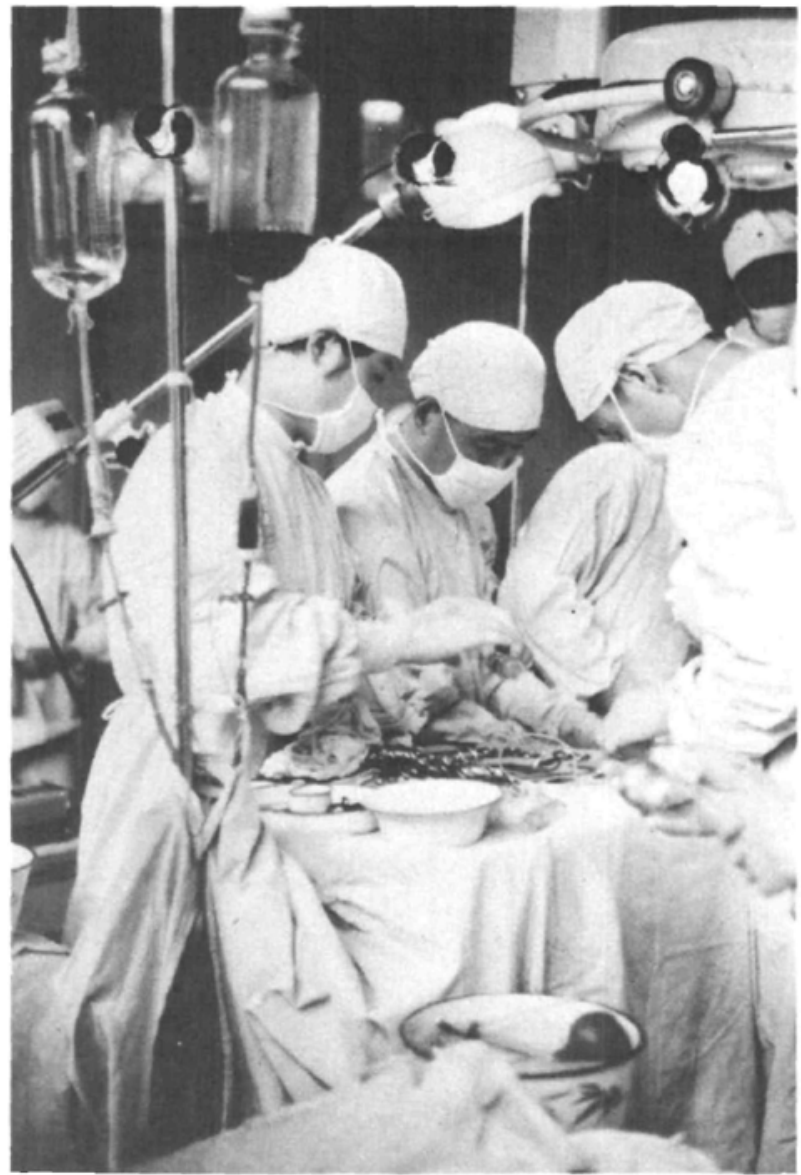

Figune 5. Blood and glucose solution being infused through non-disposable tubing. Glass beads are replacing the filter in the drip chamber of the blood transfusion set. Note that containers are refillable from the top. The intravenous fluid administration as a rule is into a lower extremity.

\section{Disadvantages of acupuncture anaesthesia}

These are freely admitted by the Chinese and basically relate to three shortcomings.

1. Incomplete analgesia. While acupuncture raises the pain threshold, in most instances it does not provide complete analgesia. This, of course, is evident from the figures quoted in Tables I and II. It is interesting to note that, despite these failings, the use of acupuncture anaesthesia has continued to increase in the People's Republic of China. One might well ask why this should be so. One factor, of course, is its obvious superiority when compared to the rather primitive type of general anaesthesia available in most hospitals and the shortage of adequately trained and qualified medical personnel. Consequently, its comparative safety vis-a-vis "drug" anaesthesia is markedly raised. However, a more compelling factor is that the promotion of acupuncture anaesthesia as a unique contribution 
to medicine by the New China has major political overtones. This statement can probably best be corroborated by the great increase of acupuncture anaesthesia since April 1976 and the political defeat at that time of the so-called "revisionist line." Indeed, we were informed with great pride that in one institution the percentage of acupuncture anaesthesia for neurosurgical operations since that particular time had jumped from 10 per cent to 61 per cent, surely an indication of the political dedication of the medical team to what is called "correct verdicts."

2. The second drawback of acupuncture anaesthesia is that visceral sensation from traction on or manipulation of internal organs is not controlled. This makes it impossible to explore the abdomen in a systematic fashion and the operation is carried out on the basis of the pre-operative diagnosis alone. In order to make it possible to carry out gastrectomies the surgeons have adapted their operative technique by minimizing the exteriorization of peritoneal contents, using now exclusively a modified Bancroft procedure.

3. Lastly, muscle relaxation is poor. This is another reason why adequate abdominal exploration is impossible and why intestinal manipulation must be reduced to a minimum, since any painful stimulus will increase muscle rigidity. If tightness interferes with closure of the peritoneum, 1 per cent procaine is commonly infiltrated.

Finally the question is often asked how it is possible to carry out thoracotomies without positive pressure ventilation. The secret seems to lie in extensive pre-operative breathing exercises in which the patient is taught to breathe entirely with his diaphragm to the exclusion of thoracic breathing. In cardiac operations in addition the open pericardium is sutured to the chest wall, which adds stability to the mediastinum, and when possible a median sternotomy is used and opening of the pleurae thus avoided. It might be mentioned here that in some thoracic operations tracheal intubation and positive pressure ventilation are carried out in the presence of acupuncture analgesia; patients seem to tolerate this combination well.

It is only fair to state at this point that a considerable number of operations are still being done under general or regional anaesthesia in areas in which acupuncture anaesthesia has been found inadequate and also that quite modern anaesthesia facilities are available in some specialized hospitals. We were impressed, however, by the absence of Recovery Rooms, Intensive Care Units, respirators and monitors except, again, in a few specialized institutions. Monitoring of central venous pressure, electrocardiogram, etc. was seen only in open-heart operations. No disposable equipment is used in China and this includes equipment for the administration of intravenous fluids and blood (Figure 5).

In conclusion one can say without hesitation that acupuncture anaesthesia for surgical operations in the present state of the art has no place in the Operating Rooms of those countries in which adequate and skilled modern anaesthesia is available. In view of the potential use which can be made of acupuncture analgesia in other areas, especially those of pain treatment, one cannot help but feel that it is a psychological and practical error on the part of the Chinese to try so hard to export indiscriminately a technique of anaesthesia which, if adopted elsewhere, would constitute in many countries a major regression in the standards prevailing at the present time. 
Only at the Shanghai Physiological Institute have we seen investigative work of a high scientific calibre being done in China, aimed at elucidating the basic mechanisms of acupuncture. There is now good experimental evidence that interaction between pain and acupuncture stimuli takes place at the level of the spinal cord, the reticular formation, and in the nucleus parafascicularis and centralis lateralis in the thalamus. The role of higher centres has not been clearly defined as yet. Furthermore, cross-circulation experiments would lead one to believe that humoral factors also are involved in the process and this assumption is further strengthened by the ability to transmit analgesia produced by acupuncture in animals by means of cross-infusion of cerebrospinal fluid. Finally, neuro-transmitters have also been shown to play a role, particularly 5-HT (serotonin), aminoacids, and acetylcholine, although the extent of involvement of each of these has not yet been definitely determined.

The entire area of scientific investigation into the phenomenon of acupuncture is at a very early stage and a good deal more work will be required in this area. How much of this will come out of Chinese laboratories and how much will be contributed by the West is anybody's guess. One has the definite impression that truly open-minded, scientific medical investigation has a low official priority of encouragement and facilities are not exactly over-abundant. Let it also not be forgotten that there still exists a sizeable, if not a majority opinion who believe firmly in the existence of channels and collaterals. While arguments are based largely on historical precedence and clinical deductions, yet much energy is being diverted into proving their existence.

\section{SUMMary}

Acupuncture has been described as it is practiced in the People's Republic of China. To understand fully the preoccupation of the Chinese with this mode of treatment one must be familiar with its economic, historical and cultural background. Since conditions in Western countries are totally different from those in China it is obvious that acupuncture cannot be transplanted in toto from country to country, but that it requires reassessment of its usefulness as a treatment modality. Although further basic and clinical studies must be carried out, it would appear at the moment that acupuncture may have a useful place as yet an additional means of treating pain, especially in areas in which present treatment is less than satisfactory. At the moment no clear indication is obvious for acupuncture anaesthesia in countries in which this specialty is well developed and where adequate numbers of trained anaesthetists are available.

\section{RÉSUMÉ}

Les auteurs décrivent dans cet article le mode de pratique de l'acupuncture en République Populaire de Chine. Ils dressent le tableau des traits économiques, historiques et culturels qui permettent de comprendre l'importance que donnent 
les Chinois à l'étude et à l'application de cette modalité thérapeutique. Il apparaît essentiel que la place réelle de l'acupuncture soit défnie dans l'arsenal thérapeutique de chaque pays avant de passer à une application qui soit calquée sur celle de la Chine Populaire puisque les conditions de santé prévalentes en Occident sont fort différentes de celles de la Chine. Il semble à l'heure actuelle que l'acupuncture puisse être utile comme moyen de soulager la douleur et ce surtout dans les syndromes où le traitement classique reste insatisfaisant. Des études plus poussées doivent cependant être entreprises dans le domaine des sciences de base de même que dans celui des sciences cliniques afin de documenter cet effet analgésique. Il ne semble pas cependant évident que l'on doive utiliser l'anaesthésie par acupuncture dans les pays où la spécialité de l'anesthésie est suffisamment développée et où un nombre suffisant d'anesthésistes peut répondre aux besoins de la population. 